\title{
Co-trimoxazole in rheumatoid arthritis: a comparison with sulphapyridine
}

\author{
C ASTBURY, J HILL, AND H A BIRD
}

From the Clinical Pharmacology Unit, Royal Bath Hospital, Cornwall Road, Harrogate, and General Infirmary at Leeds, Leeds

SUMMARY The antirheumatoid activity of sulphasalazine and sulphapyridine may result from their antibacterial properties. The second line activity of sulphamethoxazole, in the form of cotrimoxazole (CTZ), has been investigated by treatment of 13 patients with RA for 24 weeks with CTZ (480 mg three times a day). The drug was found to be poorly tolerated, only five of the thirteen patients recruited completing the study. High circulating concentrations of sulphamethoxazole were found, with mean (SD) steady state serum concentrations reaching 54.02 $(23.38) \mu \mathrm{g} / \mathrm{ml}$. A significant reduction in serum IgM from 280 to $130 \mathrm{IU} / \mathrm{l}$ was observed, but otherwise disease activity remained unchanged or deteriorated throughout the course of the study. In contrast, patients with RA treated with sulphapyridine $(1.25 \mathrm{~g}$ a day) showed improvement in disease activity. The results argue against an antibacterial mechanism of action for sulphasalazine and sulphapyridine in rheumatoid arthritis, unless this occurs at a site inaccessible to sulphamethoxazole.

Key word: sulphonamides.

Sulphasalazine has been shown to have specific antirheumatoid activity. ${ }^{1-6}$ The mechanism of action of sulphasalazine in rheumatoid arthritis (RA) is unknown, but there is evidence from two independent studies that sulphapyridine (SP), the sulphonamide component of the sulphasalazine molecule, is the active agent. $^{78}$ In addition, 5-aminosalicylic acid, the salicylate moiety of sulphasalazine, does not display second line activity in RA. ${ }^{9}$ If SP is effective in treating RA through its antimicrobial properties it may be expected that other sulphonamides with a similar antimicrobial spectrum of activity may also have antirheumatoid properties, provided that they are accessible to the same site or sites of action as SP. Sulphamethoxazole is such a drug.

In 1972 Kalliomaki suggested that the addition of co-trimoxazole (CTZ) (1.44 g/day) to the treatment regimen of patients with $\mathrm{RA}$ already receiving treatment with gold, chloroquine, or steroids led to a significant reduction in erythrocyte sedimentation rate and an increase in grip strength. ${ }^{10}$ More recently, Ash et al have shown clinical and biochemical improvement of disease activity in a

Accepted for publication 14 October 1987

Correspondence to $\mathrm{Dr} \mathrm{H}$ A Bird, Clinical Pharmacology Unit, Royal Bath Hospital, Cornwall Road, Harrogate HG1 2PS group of 23 patients with RA treated with sulphamethoxazole (SM) (2 g/day), the sulphonamide component of CTZ."

The aim of this study was to confirm whether CTZ has second line activity in patients with RA not receiving other second line drugs, by a study protocol previously designed to evaluate possible antirheumatoid activity of various drugs. ${ }^{12}$

\section{Patients and methods}

Thirteen patients with classical or definite RA (American Rheumatism Association criteria), who had not received a second line drug over the preceding three months, were recruited to the study. Each patient was treated with $480 \mathrm{mg} \mathrm{CTZ}$ (Bactrim, Roche) three times a day and monitored for changes in clinical and biochemical indices of disease activity at regular intervals over a period of 24 weeks (Table 1). All clinical observations throughout the trial were carried out by the same clinical metrologist. Side effects were determined by routine haematology and biochemistry and by asking each patient at each visit to clinic the standard question: "Have the tablets upset you in any way?".

At the end of the study period, changes in disease activity for each patient were assessed by applying 
regression analysis to determine the degree of change of each parameter during treatment. A one sample, one way Student's $t$ test was used to assess the significance of trends. Patients withdrawing from the trial before week 8 were excluded from statistical analysis.

Serum samples of patients completing more than eight weeks' treatment with CTZ were analysed for SM and acetylsulphamethoxazole (AcSM) concentrations by high performance liquid chromatography. ${ }^{13}$

The results obtained were compared with those obtained with SP ( $1.25 \mathrm{~g} /$ day $)$ in RA using the same study protocol, with identical admission criteria. ${ }^{8}$ The clinical and laboratory investigators were the same in both studies. Differences in disease activity and age of patients in the two treatment groups before the onset of therapy were determined by the Mann-Whitney U test.

The dose of SP (1.25 g/day) selected is equivalent to $2 \mathrm{~g} /$ day sulphasalazine, the standard maintenance $\frac{\mathrm{O}}{\mathrm{n}}$ dose in RA. The dose of CTZ $(1.44 \mathrm{~g} /$ day $)$ was chosen for two reasons: $(a)$ the dose of SM used by Ash ( $2 \mathrm{~g} /$ day) was found to be too toxic for longo term use, and Kalliomaki had demonstrated음 improvement in disease activity with CTZ $1.44 \mathrm{~g} /$ day: (b) it was comparable with the dose of SP in moles $\mathbb{Q}$ of each sulphonamide (Table 2).

\section{Results}

SIDE EFFECTS

It was originally intended to include 15 patients in the CTZ study, but owing to an overall lack of response to treatment and a high frequency of side effects, recruitment was restricted on ethical. grounds to 13 patients. Only nine patients progressedi beyond eight weeks' treatment with CTZ. During the course of the trial most patients developed some응 form of gastrointestinal disturbance or bruising, rash, itching, or mouth ulceration.

Table 1 Summary of the clinical and biochemical assessments of disease activity, recorded at each clinic visit

\begin{tabular}{lll}
\hline Parameter & Abbreviation & Method \\
\hline Clinical & & Sphygmomanometer cuff \\
Grip strength & GS & Ritchic \\
Articular index & AI & Arthrocircometer \\
PIP* joint circumference & JS & Modified visual analoguc scalc \\
Total change score & TCS & Daily diary card \\
Pain score & PAIN & Daily diary card \\
Early morning stiffness & EMS & \\
& & \\
Biochemical & FBC & Coulter autoanalyser \\
Full blood count & Hb & Coulter autoanalyser \\
Haemoglobin & ESR & Westergren \\
Erythrocyte sedimentation rate & PV & Capillary viscometcr \\
Plasma viscosity & CRP & Radial immunodiffusion \\
Serum C reactive protein & Igs & Radial immunodiffusion \\
Serum immunoglobulins & HIST & Spectrofluorimeter \\
Serum histidine & SH & Spectrophotometer \\
Total serum sulphydryl & & Vickers autoanalyser \\
Plasma electrolytes & PROT & Vickers autoanalyser \\
Plasma proteins & LFT & Vickers autoanalyser \\
Liver function tests & GGTP & Spectrophotometer \\
$\gamma$-Glutamyltranspeptidase & & \\
\hline
\end{tabular}

${ }^{*} \mathrm{PIP}=$ proximal interphalangeal.

Table 2 Mean (SD) steady state serum concentrations of sulphapyridine and sulphamethoxazole and their acetyl $\frac{0}{\subset}$ metabolites in patients with $R A$

\begin{tabular}{|c|c|c|c|}
\hline & Sulphapyridine & Sulphamethoxazole & p Value* \\
\hline Dose (mmol/day) & $5 \cdot 01$ & $4 \cdot 74$ & \\
\hline Free sulphonamide $(\mu \mathrm{g} / \mathrm{ml})$ & $14 \cdot 12(8 \cdot 19)$ & $54 \cdot(12(23 \cdot 38)$ & $<0 \cdot(0) 1$ \\
\hline Acetyl metabolite $(\mu \mathrm{g} / \mathrm{ml})$ & $10.89(6.22)$ & $17.62(6.76)$ & $<0 \cdot(0) 1$ \\
\hline Total sulphonamide $(\mu \mathrm{g} / \mathrm{ml})$ & $25 \cdot(02(10 \cdot 44)$ & $71.63(27.73)$ & $<0 \cdot(001$ \\
\hline
\end{tabular}

*Two sample Student's $t$ test. 
Table 3 Median (range) changes in disease activity during 24 weeks' treatment with co-trimoxazole (1.44 g/day) or sulphapyridine (1.25 g/day)

\begin{tabular}{|c|c|c|c|c|c|c|}
\hline \multirow[t]{2}{*}{ Parameter } & \multicolumn{3}{|c|}{ Co-trimoxazole } & \multicolumn{3}{|c|}{ Sulphapyridine } \\
\hline & Week 0 & Week 24 & $p$ Value & Week 0 & Week 24 & p Value \\
\hline AI & $\begin{array}{l}21 \\
(7-37)\end{array}$ & $\begin{array}{l}26 \\
(11-40)\end{array}$ & $<0 \cdot\left(005^{*}\right.$ & $\begin{array}{l}27 \\
(5-47)\end{array}$ & $\begin{array}{l}18 \\
(0-50)\end{array}$ & $<0 \cdot 005$ \\
\hline $\mathrm{JS}(\mathrm{mm})$ & $\begin{array}{l}66 \\
(60-82)\end{array}$ & $\begin{array}{l}68 \\
(54-84)\end{array}$ & NS & $\begin{array}{l}61 \\
(54-64)\end{array}$ & $\begin{array}{l}57 \\
(52-64)\end{array}$ & $<0 \cdot 025$ \\
\hline EMS $(\min )$ & $\begin{array}{l}53 \\
(0-600)\end{array}$ & $\begin{array}{l}96 \\
(0-600)\end{array}$ & NS & $\begin{array}{l}115 \\
(0-420)\end{array}$ & $\begin{array}{l}4 \\
(0-38)\end{array}$ & NS \\
\hline $\mathrm{GS}(\mathrm{mmHg})$ & $\begin{array}{l}96 \\
(51-122)\end{array}$ & $\begin{array}{l}86 \\
(51-136)\end{array}$ & NS & $\begin{array}{l}102 \\
(56-148)\end{array}$ & $\begin{array}{l}116 \\
(61-200)\end{array}$ & $<0.005$ \\
\hline PAIN & $\begin{array}{l}3 \\
(1-4)\end{array}$ & $\begin{array}{l}3 \\
(2-4)\end{array}$ & NS & $\begin{array}{l}3 \\
(2-5)\end{array}$ & $\begin{array}{l}2 \\
(1-3)\end{array}$ & $<0.025$ \\
\hline TCS & 100 & $\begin{array}{l}107 \\
(-24-176)\end{array}$ & NS & 100 & $\begin{array}{l}104 \\
(96-110)\end{array}$ & $<0 \cdot 010$ \\
\hline CRP (mg/l) & $\begin{array}{l}<0 \cdot 5 \\
(<0 \cdot 5-60 \cdot 0)\end{array}$ & $\begin{array}{l}6.9 \\
(<0 \cdot 5-36 \cdot 6)\end{array}$ & NS & $\begin{array}{l}27 \cdot 5 \\
(0 \cdot 0(0)-74 \cdot 5)\end{array}$ & $\begin{array}{l}<0.5 \\
(0.00-69.0)\end{array}$ & NS \\
\hline $\mathrm{Hb}(\mathrm{g} / \mathrm{l})$ & $\begin{array}{l}105 \\
(97-124)\end{array}$ & $\begin{array}{l}111 \\
(102-133)\end{array}$ & NS & $\begin{array}{l}113 \\
(103-136)\end{array}$ & $\begin{array}{l}119 \\
(112-151)\end{array}$ & NS \\
\hline HIST (mg/l) & $\begin{array}{l}11 \cdot 8 \\
(8 \cdot 6-13 \cdot 1)\end{array}$ & $\begin{array}{l}11 \cdot 3 \\
(7 \cdot 5-13 \cdot 4)\end{array}$ & NS & $\begin{array}{l}11 \cdot 5 \\
(8 \cdot 9-17 \cdot 5)\end{array}$ & $\begin{array}{l}16 \cdot 9 \\
(15 \cdot 0-19 \cdot 5)\end{array}$ & $<0 \cdot 0005$ \\
\hline PV (cP) & $\begin{array}{l}2 \cdot 00 \\
(1 \cdot 82-2 \cdot 23)\end{array}$ & $\begin{array}{l}2 \cdot 10 \\
(1 \cdot 9()-2 \cdot 41)\end{array}$ & NS & $\begin{array}{l}1 \cdot 95 \\
(1 \cdot 83-2 \cdot 20)\end{array}$ & $\begin{array}{l}1.72 \\
(1.60-1.91)\end{array}$ & $<0 \cdot 0005$ \\
\hline $\mathrm{SH}(\mu \mathrm{mol} / \mathrm{l})$ & $\begin{array}{l}325 \\
(240-415)\end{array}$ & $\begin{array}{l}390 \\
(285-455)\end{array}$ & NS & $\begin{array}{l}295 \\
(175-415)\end{array}$ & $\begin{array}{l}410 \\
(235-625)\end{array}$ & $<0 \cdot 025$ \\
\hline IgM (IU/I) & $\begin{array}{l}280 \\
(90-650)\end{array}$ & $\begin{array}{l}130 \\
(72-535)\end{array}$ & $<0 \cdot(005$ & $\begin{array}{l}225 \\
(50-425)\end{array}$ & $\begin{array}{l}120 \\
(45-370)\end{array}$ & $<0) \cdot(005$ \\
\hline
\end{tabular}

${ }^{*}$ Denotes detcrioration in disease activity.

†Table 1 lists the abbreviations.

DISEASE ACTIVITY

Changes in disease activity during treatment were determined by regression analysis ${ }^{14}$ because of the high number of patients withdrawing from the trial.

Of the patients completing a minimum of eight weeks' treatment with CTZ, the only significant improvement in disease activity was in serum immunoglobulins, IgM falling from a median of 280 IU/l at week 0 to $130 \mathrm{IU} / \mathrm{l}$ at week $24(\mathrm{p}<0 \cdot 005)$. There was a deterioration in disease activity as judged by increases in articular index, early morning stiffness, proximal interphalangeal joint circumference, and plasma viscosity, and a fall in grip strength, but only the increase in articular index reached statistical significance (Table 3 ). None of the patients actually felt that CTZ had improved their condition, and no patient elected to remain on the drug at the end of the study.

There was no significant difference in the disease activity or age of patients before onset of treatment with CTZ or SP (Mann-Whitney U test). In contrast with patients treated with CTZ, there was an improvement in disease activity in patients during treatment with SP (Table 3).

STEADY STATE CONCENTRATIONS

There was a 10 -fold interpatient variation in steady state serum SM concentrations, and a threefold variation in serum AcSM concentrations. The mean steady state circulating concentration of free sulphonamides was considerably greater than that found in the group of patients treated with SP (Table 2).

There was no correlation between serum concentrations of SM or AcSM and the incidence of side effects.

\section{Discussion}

All sulphonamides are structural analogues of $p$ aminobenzoic acid, required by certain bacteria as a precursor for the synthesis of folic acid. They compete with $p$-aminobenzoic acid for the enzyme dihydropteroate synthetase and hence inhibit folic acid production. They may also become incorporated into the folate molecule in place of $p$ aminobenzoic acid, forming a 'false folate', interfering in subsequent reactions with folic acid. The $p$ amino $\left(\mathrm{N}_{4}\right)$ group of the sulphonamide molecule has to be unmasked for antimicrobial activity. Thus sulphasalazine has little antimicrobial action until SP is liberated by azo reduction within the lower gastrointestinal tract. The sulphonamides have a broad spectrum of antibacterial activity, and the 
choice of sulphonamide for use in infection depends on pharmacokinetic properties rather than on differences in antibacterial activity.

It was unfortunate that side effects and ethical considerations rendered a relatively small number of patients suitable for analysis. All patients had active disease, judged by a majority of criteria, and the groups were matched for abnormality of plasma viscosity and other laboratory parameters if not for $\mathrm{C}$ reactive protein. Despite these reservations we still judge CTZ less effective than SP in the treatment of RA.

The results obtained with CTZ in RA were disappointing as Kalliomaki had reported success with $\mathrm{CTZ}^{10}$ and Ash et al with SM. ${ }^{11}$ Possible reasons for this discrepancy are (a) Kalliomaki used patients already receiving second line agents or steroids, $(b)$ the dose of SM used by Ash was $60 \%$ greater than that used in this study ( $2 \mathrm{~g} /$ day compared with $1.2 \mathrm{~g} /$ day).

A dose of this magnitude may be therapeutically effective in RA, but many of his patients developed hepatotoxicity, not seen with the more moderate dosage regimen used in our study. If the higher dose of SM has second line activity in RA, this suggests the risk/benefit ratio of SM in RA is very close, and will limit the use of the drug in this disease.

The antibacterial activity of the sulphonamides is dependent on the $\mathrm{pH}$ of the environment, the electrochemical properties of the $\mathrm{N}_{1}$ substituted radical, and the acid dissociation constant $(\mathrm{Ka})$ of the sulphonamide molecule. It has been predicted that SM (pKa 5.7) may have greater antibacterial activity in an acidic medium, whereas SP (pKa 8.4) may be more effective in an alkaline medium. At physiological $\mathrm{pH}$ the antibacterial activities of the two sulphonamides are predicted to be very similar. ${ }^{15}$

Orally administered SM is rapidly and almost totally absorbed. Ninety per cent of an administered dose can be recovered in the urine after $800 \mathrm{mg} \mathrm{SM}$ twice a day. ${ }^{16}$ The absorption of SP is slow and inconsistent, ${ }^{17}$ and only $67 \%$ of a single dose of SP ( $4 \mathrm{~g}$ orally) can be recovered in the urine. ${ }^{14}$ This may account for the considerably greater steady state serum concentrations of SM than SP after almost equimolar doses of the two sulphonamides (Table 2). If SP is effective in RA through an antimicrobial action, SM may have failed to provide benefit because it failed to reach therapeutic concentrations at the critical site of action, even though it attained greater systemic bioavailability. This site is unlikely to be the synovium as the ratio of steady state SM concentrations in synovial fluid and plasma is $1: 1^{16}$ and the corresponding ratio for SP is $0 \cdot 87: 1{ }^{18} \mathrm{SM}$ will be present in considerably greater concentrations than SP within the synovium. Alternatively, the site of action may be within the $\vec{F}$ gastrointestinal tract. This would support the $\stackrel{0}{?}$ hypothesis that RA may be an enteropathic arthropathy. ${ }^{19-2.3}$ Rapid absorption of SM in the $\overline{\underline{\sigma}}$. upper intestinal tract may prevent it reaching a site $\frac{0}{7}$ in the lower bowel where SP may be acting. The $\mathbb{Q}$ higher dose of SM used by Ash et al ${ }^{11}$ may have enabled therapeutic amounts of SM to reach the $\vec{O}$ more alkaline lower bowel.

Exacerbations of RA may result from microbial $\overrightarrow{\vec{\omega}}$ stimuli within the gut. The progression of the $\frac{D}{2}$ disease may then be enhanced by the release of bacterial toxins which act by activation of cell is membrane phospholipase, inducing synthesis of leucotrienes, prostaglandins, and thromboxanes. Further clarification of the mechanism of action of $\underset{\omega}{ }$ $\mathrm{SP}$ in RA within the gut may come either from a trial 은 of a 'non-absorbable' sulphonamide with a $\mathrm{pKa}>7$, or from the use of a colonic release preparation of a non-sulphonamide antibiotic with an antimicrobial spectrum similar to that of the sulphonamides.

The authors wish to thank Dr A J Taggart for clinical assistance and Dr J S Dixon for help in preparing this manuscript. CA acknowledges the financial support of the Arthritis and Rheumatism Council. The Clinical Pharmacology Unit is supported by Roche Products Ltd.

\section{References}

1 McConkey B. Amos R S. Butler E P. Crockson R A, Crockson A P. Walsh L. Salazopyrin in rheumatoid arthritis. Agents Actions 1978: 8: 438-41.

2 McConkey B, Amos R S. Durham S, Forster P J G, Hubball S. Walsh L. Sulphasalazine in RA. Br Med J 1980; 280: 442-4.

3 Bird H A. Dixon J S. Pickup M E, et al. A biochemical assessment of sulphasalazine in rheumatoid arthritis. $J$ Rheumatol 1982: 9: 36-45.

4 Neumann V C, Grindulis K A. Hubball S, McConkey B, Wright $\mathrm{V}$. Comparison between penicillamine and sulphasalazine in rheumatoid arthritis: Leeds-Birmingham trial. $\mathrm{Br}$ Med J 1983; 287: 1099-102.

5 Pullar T, Hunter J A, Cappell H A. Sulphasalazine in rheumatoid arthritis: double-blind comparison of sulphasalazinc with placebo and sodium aurothiomalate. $\mathrm{Br}$ Med $J$ 1983; 287: $1102-4$.

6 Bax D E. Amos R S. Sulphasalazine: a safe, effective agent for prolonged control of rheumatoid arthritis. A comparison with sodium aurothiomalatc. Ann Rheum Dis 1985; 44: 194-8.

7 Pullar T, Hunter J A. Cappell H A. Which component of sulphasalazinc is active in rheumatoid arthritis? Br Med J 1985; 290: $1535-8$.

8 Neumann V C. Taggart A J, Le Gallez P, Astbury C, Hill J, Bird $\mathrm{H}$ A. A study to determine the active moicty of $\mathscr{D}$ sulphasalazine in rheumatoid arthritis. J Rheumatol 1986; 13: 285-7.

9 Situnayake R D. McConkey B. Resin-coated 5-aminosalicylic acid (Asacol) in rheumatoid arthritis. Br J Rheumatol 1985; 24: 226-7.

10 Kalliomaki J L. A therapeutic trial with a combination of trimethoprim-sulphamethoxazole in rheumatoid arthritis. Current Therapeutic Research (New York) 1972; 14: 22-5.

11 Ash G, Baker R, Rajapakse C. Swinson D R. Study of 
sulphamethoxazole in rheumatoid arthritis. $\mathrm{Br} J$ Rheumatol 1986; 25: 285-7.

12 Dixon J S, Bird H A, Pickup M E, Wright V. A human model screening system for the detection of specific anti-rhcumatic activity. Semin Arthritis Rheum 1982; 12: 185-9.

13 Astbury C. Dixon J S. A rapid HPLC method for the determination of either sulphapyridine or sulphamethoxazole and their acetyl metabolites. J Chromatogr 1987; 414: 223-7.

14 Frisk A R. Blood concentration, acetylation and urinary excretion of sulphapyridine and sulphathiazole after various sulphapyridine and sulphathiazole derivatives administered by different routes. Acta Med Scand 1941; 56: 369-95.

15 Bell P E. Roblin R O Jr. Studies in chemotherapy. VII. A theory of the relation of structure to activity of sulfanilamide type compounds. Journal of the American Chemical Society 1942; 64: 2905-17.

16 Reeves D S, Wilkinson P J. Pharmacokinctics of trimethoprim/ sulphonamide combinations, including penetration into body tissues. Infection 1979; 7: S330-41.
17 Reynolds J E F (cd). Martindale. The Extra Pharmacopoeia, 28th ed. London: Pharmaceutical Press. 1982.

18 Farr M, Brodrick A. Bacon P A. Plasma and synovial fluid concentrations of sulphasalazine and two of its metabolites in rheumatoid arthritis. Rheumatol Int 1985; 5: 247-51.

19 Olhagen B. Mansson I. Intestinal Clostridium perfringens in rheumatoid arthritis and other collagen diseases. Acta Med Scand 1968; 184: 395-402.

20 Anonymous. Rheumatoid arthritis and the gut [Editorial]. $\mathrm{Br}$ Med J 1979; i: 1104.

21 Shinebaum R. Faecal flora and the rheumatic diseases. Univ Leeds, 1985. (PhD thesis.)

22 Zaphiropoulos G C. Rheumatoid arthritis and the gut. $\mathrm{Br} \mathrm{J}$ Rheumatol 1986; 25: 138-9.

23 Segal A W, Isenberg D M, Hajarousou V, Tolfree S. Clark J. Snaith M L. Preliminary evidence for gut involvement in rheumatoid arthritis. Br J Rheumatol 1986; 25: 162-6. 